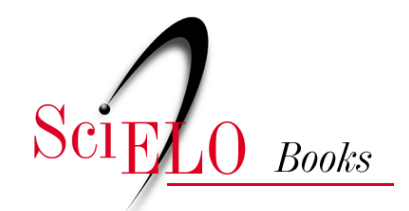

uer

\title{
O bairro de Santa Cruz, RJ uma configuração socioespacial construída no decorrer do tempo
}

\author{
Vânia Regina Jorge da Silva
}

\section{SciELO Books / SciELO Livros / SciELO Libros}

SILVA, V.R.J. O bairro de Santa Cruz, RJ: uma configuração socioespacial construída no decorrer do tempo. In: MARAFON, G.J., and RIBEIRO, M.A. orgs. Revisitando o território fluminense, VI [online]. Rio de Janeiro: EDUERJ, 2017, pp. 167-188. ISBN: 978-85-7511-457-5.

https://doi.org/10.7476/9788575114575.0010.

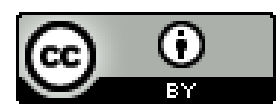

All the contents of this work, except where otherwise noted, is licensed under a Creative Commons Attribution 4.0 International license.

Todo o conteúdo deste trabalho, exceto quando houver ressalva, é publicado sob a licença Creative Commons Atribição $\underline{4.0}$.

Todo el contenido de esta obra, excepto donde se indique lo contrario, está bajo licencia de la licencia $\underline{\text { Creative Commons }}$ $\underline{\text { Reconocimento 4.0. }}$. 


\section{0 bairro de Santa Cruz, RJ: uma configuração socioespacial construída no decorrer do tempo}

Vânia Regina Jorge da Silva

\section{Introdução}

- ste artigo analisa e caracteriza as condições socioeconômicas e fisiográficas do bairro ${ }^{1}$ de Santa Cruz, situado no extremo oeste da cidade do Rio de Janeiro. A importância desta análise se deve a dois fatores.

O primeiro, porque esse bairro, assim como a área em que se encontra inserido, a Zona Oeste carioca (Figura 1), apresenta baixa densidade demográfica em relação a outras da urbe, constituindo-se, portanto, em extensão com prognóstico de expansão urbana.

O segundo fator diz respeito à sua localização em relação a importantes investimentos de infraestrutura: a instalação da Companhia Siderúrgica do Atlântico (CSA); a remodelação do Porto de Itaguaí; e a construção do túnel Vice-Presidente José Alencar (da Grota Funda), da TransOeste e do Arco Rodoviário Metropolitano do Rio de Janeiro (ARMRJ), alguns já em operação e outros ainda em construção nesta segunda década do século XXI.

Esses fatores se consubstanciam em autênticos indutores de mudanças na configuração socioespacial na direção oeste tanto do município do Rio de Janeiro como da Região Metropolitana homônima. Assim, nas pesquisas realizadas, ${ }^{2}$ reconhecemos que a Zona Oeste carioca está passando

${ }^{1}$ Referimo-nos ao bairro como a menor porção delimitada e reconhecia pela divisão político-administrativa do município do Rio de Janeiro.

2 Este artigo integra a tese desenvolvida no Programa de Pós-Graduação em Geografia da UERJ, intitulada "O bairro de Santa Cruz-RJ no contexto da metropolização: escalas, dinâmicas e processos socioespaciais (2005-2015)”. 
por um momento de expansão urbana específica, que demanda maior exame em comparação com processos anteriores.

É necessário, contudo, retroagirmos um pouco, a fim de entendermos os diversos tempos espacializados em justaposição que explicam a atual configuração espacial desse recorte de estudo. Tomamos como referência teórica Milton Santos (2008) quanto à evolução histórica, à modernização e às inovações tecnológicas, como elementos que conferem periodização ao espaço, a fim de apreendê-lo como produto e condiçãao eficaz e ativa para a concreta realização de produção, influenciando os momentos seguintes. Entende-se, portanto, que o espaço não é tão somente reflexo social, mas também resultado de contextos específicos pretéritos, que se tornam condicionantes e intervenientes em relação aos processos posteriores. Em outras palavras, em conjunturas político-econômicas nacionais específicas, podemos observar estratégias que impactaram o território fluminense como um todo, e o bairro de Santa Cruz em particular, atribuindo-lhe uma estrutura que intervém no presente momento. A esse respeito, acrescentamos que, de acordo com Léfebvre (1994), o espaço também é um campo de ação, um instrumento político, produto social que intervém na produção capitalista, na reprodução da sociedade e na reprodução das relações sociais de produção, ou seja, é produto e também condição.

Nesse contexto, com o objetivo de apreender a realidade atual como resultante de contextos específicos de urbanização anteriores e de observar como esse quadro interfere na atual fase de expansão urbana, são consideradas a localização e as condições socioeconômicas do bairro de Santa Cruz frente à composição espacial da cidade do Rio de Janeiro, de parte da Região Metropolitana e do estado do Rio de Janeiro. Além disso, apresentam-se um quadro fisiográfico da área em estudo que interfere em sua ocupação e também sua posição dentro do recorte denominado bacia de Sepetiba, que reconhecemos como uma retroárea do Porto de Itaguaí. Consideram-se ainda os principais agentes intervenientes, os dados apurados quanto à população absoluta e à densidade demográfica, bem como aqueles que dizem respeito a renda e escolaridade. Ou seja, elaboramos um quadro socioespacial descritivo que serve de base à análise dos processos espaciais em curso.

Este artigo encontra-se organizado em três partes. A primeira remete à localização de nosso recorte e à posição estratégica que ocupa na bacia de Sepetiba e no estado do Rio de Janeiro. Na segunda parte, examinamos a atual configuração socioespacial, remetendo-nos a períodos anteriores, com um breve painel da ocupação histórica dessa área e da ação estatal que lhe conferiu especificidade no contexto carioca. Fazemos também um apanhado da ocupação do solo na atualidade, com seus diferentes usos. Por fim, na terceira parte, consideramos a composição socioeconômica do bairro de Santa Cruz. Esperamos, assim, traçar um panorama que sirva de base para futuras pesquisas sobre o oeste carioca.

\section{Localização do bairro de Santa Cruz em contextos esca- lares diferentes}

O bairro de Santa Cruz encontra-se na Zona Oeste carioca (Figura 1), ladeado, a leste, pelo bairro de Paciência; ao sul, pelos bairros de Guaratiba e Sepetiba; a oeste, pela baía de Sepetiba; e, ao norte, pelos municípios de Itaguaí e Seropédica. Com a edição do Decreto-Lei no 898/1962, foi 


\section{0 bairro de Santa Cruz, RJ}

regulamentada a organização administrativa do então estado da Guanabara, hoje cidade do Rio de Janeiro. Esse decreto foi sucessivamente modificado para incluir novas divisões, até chegar à atualidade com cinco Áreas de Planejamento (AP) e $33^{3}$ Regiōes Administrativas (RA), nas quais se encontram agrupados os 161 bairros oficiais. Desse modo, Santa Cruz está inserido na Área de Planejamento 5 e, junto com os bairros de Sepetiba e Paciência, localiza-se na XIX RA de Santa Cruz.

Figura 1. Zoneamento da cidade do Rio de Janeiro

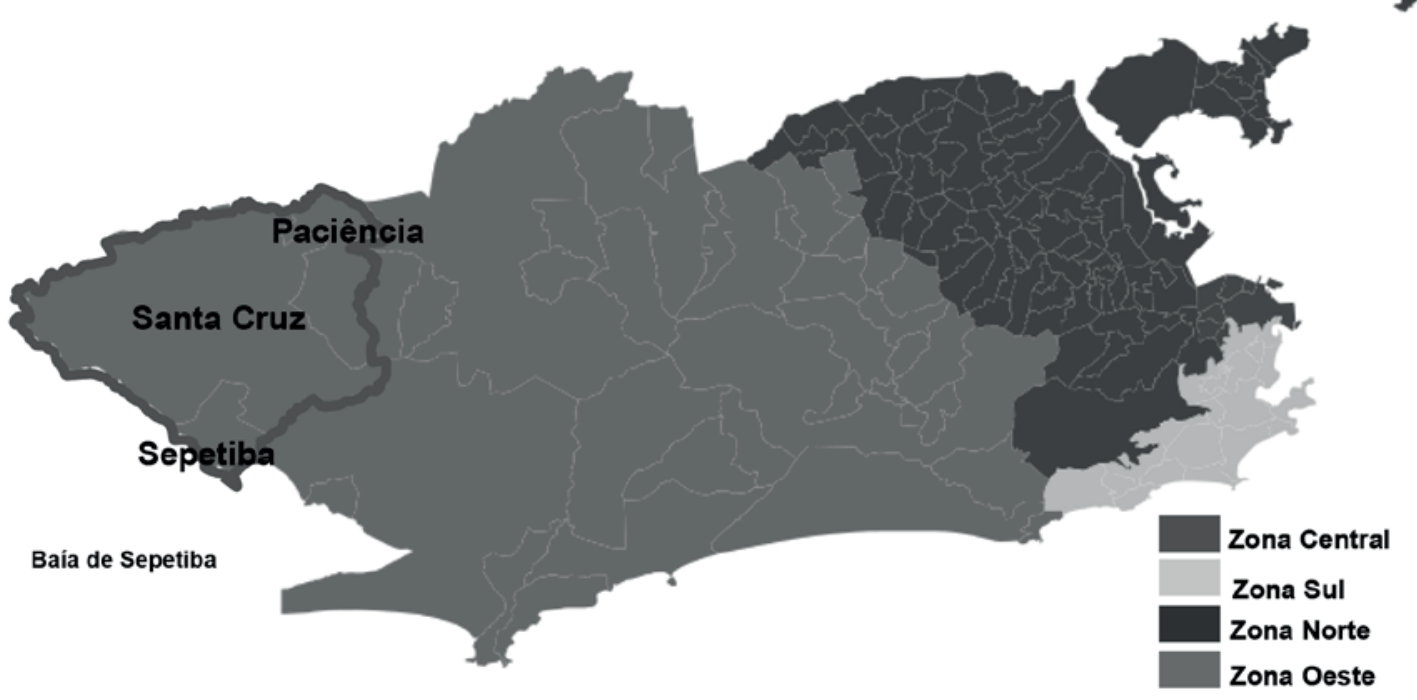

Fonte: Freire, 2011.

A extensão territorial do bairro de Santa Cruz é de 126,85 $\mathrm{km}^{2}$, representando $10,36 \%$ do território da cidade do Rio de Janeiro. Portanto, é o terceiro maior bairro carioca, sendo superado em extensão apenas por Campo Grande, com 136,52 km², e por Guaratiba, com 138,26 km². Ressaltamos que, no contexto da XIX RA de Santa Cruz, o bairro que lhe confere nome equivale a 77,32\% de sua área territorial.

Ao considerarmos a posição estratégica do bairro de Santa Cruz, remetemo-nos a dois recortes. O primeiro, o contexto do bairro na bacia de Sepetiba, e o segundo, em relação ao estado do Rio de Janeiro. Então, buscamos a análise de Machado e Castro (1996), estudo feito com o objetivo de servir

\footnotetext{
3 A XXXII RA da Colônia Juliano Moreira foi aprovada pelo Projeto de Lei no 446/96, mas não chegou a ser implementada. Portanto, até a presente data, constam 33 RAs devidamente instituídas. O projeto de lei complementar no 15/2013 tramita com a proposta de criar mais nove regiōes administrativas, desmembradas das já existentes, o que resultará no aumento da máquina administrativa, com a criação de cargos de gerência, chefia, coordenadoria e assessoria.
} 
de base a projetos de políticas de desenvolvimento, como, por exemplo, a expansão do Porto de Itaguaí. Nesse contexto, Machado e Castro tomaram como referência uma abordagem sistêmica que leva em conta os aspectos fisiográficos, econômicos e políticos-institucionais da área denominada bacia de Sepetiba, da qual o bairro de Santa Cruz faz parte. Cabe esclarecer que esse recorte é composto, em sua inteireza, pelos municípios de Seropédica, Itaguaí, Japeri, Queimados e Paracambi; por alguns dos distritos dos municípios de Engenheiro Paulo de Frontin, Mangaratiba, Miguel Pereira, Nova Iguaçu, Piraí, Vassouras e Rio Claro; e também pelas RAs de Campo Grande, Santa Cruz e Guaratiba, todas no município do Rio de Janeiro.

A importância de considerarmos o bairro de Santa Cruz nessa escala de observação nos possibilita perceber não só sua especificidade diante do todo, mas também inferir como os processos anteriores e atuais organizam e reorganizam o espaço, promovendo relações sociais que ora se espacializam em uma configuração, ora transformam-na em outra. Como exemplo, temos a localização do bairro de Santa Cruz em relação ao núcleo da metrópole e, agora, em relação a outras centralidades, que podem ser formadas e/ou reforçadas pelos processos atuais.

Machado e Castro (1996) consideram toda a área da bacia de Sepetiba como de "fronteira metropolitana”. Ou seja, essa região vem passando por um processo de urbanização que se caracteriza pela expansão da metrópole no que diz respeito a atividades econômicas e dinâmicas populacionais. A esse respeito, é interessante observar as especificidades do bairro de Santa Cruz compondo essa espacialidade. Por ser entrecortado pela av. Brasil, que faz parte da BR-101, e pela ferrovia do ramal de Santa Cruz, até a década de 1960 tinha uma função suburbana de cunho rural, com um ritmo lento de ocupação, sendo visto como parte de um "cinturão verde" composto por vários sítios e chácaras que produziam hortigranjeiros para o abastecimento do mercado carioca. Com os melhoramentos tanto da rodovia Rio-Santos como da av. Brasil, que servem como eixos de ocupação, essa área sofreu uma expansão urbana de caráter industrial, o que resultou na superposição de uma população ligada à anterior economia agrícola com melhor renda e de uma população de baixa renda devido a processos de invasão e ocupação irregular dos terrenos vazios.

Para Machado e Castro, a bacia de Sepetiba se apresenta como propícia ao desenvolvimento de uma retroárea, ou seja, uma área com estrutura logística de apoio para o porto de Itaguaí e as atividades relacionadas. Nesse contexto, percebe-se o bairro de Santa Cruz com um relevo que favorece os diferentes tipos de ocupação pelos quais o bairro tem passado desde o início da colonização, com atividades agropastoris, uso residencial, uso industrial e de comércio e serviços. Também devido aos aspectos topográficos do bairro em estudo e à ocupação irregular e clandestina para habitação, as favelas têm uma configuração horizontal.

Após tecermos essas considerações acerca do bairro em estudo no contexto da bacia de Sepetiba, devemos fazer seu enquadramento no estado do Rio de Janeiro. A esse respeito, são importantes as observações de Davidovich (2010), no sentido de que os investimentos em rodovias e portos, como os que se observam no estado, remetem-nos à ideia de que essa unidade federativa está sendo instrumentalizada como uma plataforma de exportação principalmente para produtos siderúrgicos e minerais, sobretudo de Minas Gerais, uma inflexão relativa aos momentos anteriores, pautados no mercado nacional. Ou seja, por meio de ações conjugadas por interesses públicos e privados, a cidade e o estado do Rio de Janeiro tornaram-se estratégicos para a economia globalizada. Portanto, podemos aludir ao conjunto de obras de infraestrutura, que têm o potencial de promover acentuadas alterações no recorte espacial. Como 
exemplo, citamos o ARMRJ (rodovia em construção), que não pode ser considerado isoladamente, mas apenas quando inserido em uma gama de construções, que incluem a CSA, a remodelação do porto de Itaguaí e o Comperj, entre outras, conforme visualizamos na Figura 2.

Figura 2. Investimentos no estado do Rio de Janeiro

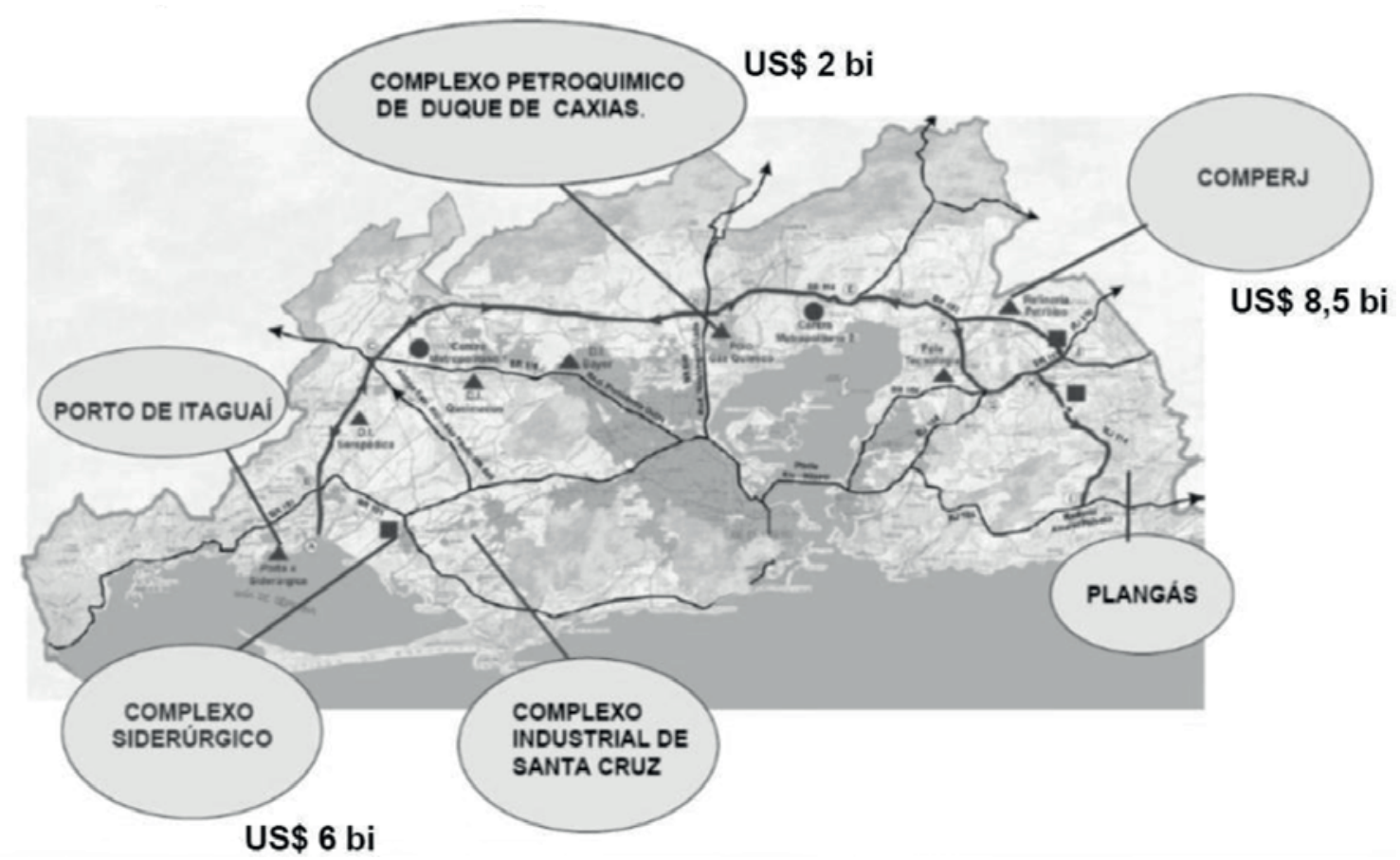

Fonte: Secretaria de Obras do Estado do Rio de Janeiro (2009).

O traçado projetado para o ARMRJ passa por oito municípios do estado do Rio de Janeiro, de Itaboraí a Itaguaí, promovendo o respectivo aumento de acessibilidade. A principal função apontada para sua construção é o acesso ao porto de Itaguaí e à malha rodoviária do país por cinco eixos rodoviários que são conectados pelo arco: a BR-101/RJ sul (Rio-Santos), a BR-465 sul (Rio-São Paulo), a BR-040/RJ (Rio-Juiz de Fora), a BR-101/RJ norte (Rio-Vitória) e a BR-116 (Rio-Bahia). De acordo com o relatório do projeto da Secretaria do Tesouro Nacional (STN), a construção dessa via é apontada como uma demanda das lideranças empresariais no estado do Rio de Janeiro, com o objetivo de ampliar a competitividade, possibilitando, assim, melhor acesso rodoviário ao porto de Itaguaí e redução dos custos de exportação de várias indústrias de Minas Gerais, Bahia e Espírito Santo.

Ao discorrermos acerca de alguns empreendimentos atrelados ao ARMRJ, remetemo-nos ao projeto de remodelação e modernização do porto de Itaguaí, que é de águas profundas, ou seja, comporta embarcaçôes com calado superior a 15 metros. Esse projeto se desdobra em diversas etapas, com investimentos do governo federal, como parte do Programa de Aceleração do Crescimento (PAC) 
desde 2008. Embora apresente ligações ferroviárias, o acesso rodoviário ainda é precário, apontando, assim, para a necessidade de se executar o projeto do ARMRJ.

Quanto à CSA, sua construção teve início em 2006 e já está em operação desde 2010. Está localizada no município do Rio de Janeiro, no distrito industrial de Santa Cruz. Essa localização se deve às inúmeras vantagens logísticas, incluindo a proximidade com algumas ferrovias e a abertura para o Oceano Atlântico (através do porto de Itaguaí), além da demanda interna por subprodutos que a usina produz, como cimento e energia, através de uma termelétrica instalada com capacidade para 490 megawatts. Observa-se que metade dessa produção é ofertada ao mercado interno. Essa empresa produz, em solo brasileiro, placas semiacabadas de aço para o suprimento de instalaçóes na Europa e nos Estados Unidos. Mais uma vez, remetemo-nos a Davidovich (2010), que ressalta o fato de que o projeto de fabricação de aços longos em Itaguaí reforça a inserção do estado Rio de Janeiro nos mercados globais, destacando a importância do recorte em estudo.

Após examinarmos o bairro de Santa Cruz nos contextos escalares do estado do Rio de Janeiro e da bacia de Sepetiba, que faz parte da RMRJ, veremos as ações relacionadas à administração pública e aos empreendimentos públicos e privados de infraestrutura que corroboram o cenário de mudança. Neste ponto, retroagimos no tempo, a fim de analisar o espaço do bairro historicamente construído.

\section{A ocupação histórica do bairro de Santa Cruz: de fazenda jesuítica a área urbana}

O bairro de Santa Cruz está situado em uma baixada formada na falha entre a serra do Mar e os maciços rochosos costeiros. As áreas deprimidas entre esses dois sistemas rochosos foram preenchidas por sedimentos que vieram das partes mais altas do relevo fluminense durante os vários ciclos de erosão-deposição correspondentes às épocas de progressão e regressão marinhas (Gama, 1998).

Em uma escala mais próxima, a da cidade do Rio de Janeiro, encontram-se alguns alinhamentos do relevo próximos ao bairro de Santa Cruz conhecidos como serra de Inhoaíba e serra da Paciência. Entre elas, estende-se uma área de baixada formada pela superposição de uma planície aluvial e uma planície litorânea. Desde o período colonial, o bairro de Santa Cruz e a área adjacente sempre estiveram funcionalmente integrados no contexto socioespacial da cidade do Rio de Janeiro e do estado homônimo. Sua principal função desde as primeiras ocupações foi a de atuar como produtor de agropecuários para a subsistência e o abastecimento da cidade (Fridman, 1999). Segundo a autora, esse recorte fazia parte da Sesmaria de Guaratiba, extensão de terras que abrigava de Itacuruçá a Guaratiba e Santa Cruz. Tratava-se de uma área estratégica, devido ao acesso à capitania de São Vicente e à rota da prata, que vinha de Buenos Aires, servindo, mais tarde, para o escoamento de ouro.

Parte dessas terras foi doada aos jesuítas, que, então, formaram uma fazenda baseada na policultura, a Fazenda de Santa Cruz. De acordo com Fridman (1999), na época em que essa área estava sob o domínio dos jesuítas, a fazenda era um grande "centro agrofabril”, funcionando como um produtor autônomo dos excedentes que escoavam por caminhos, estradas, valas, canais e rios navegáveis em direção ao mar, até chegarem à então corte, localizada no atual centro da cidade do Rio de Janeiro, e aos engenhos que existiam na então província do Rio de Janeiro (p. 188). Na Fazenda de Santa 


\section{0 bairro de Santa Cruz, RJ}

Cruz, eram desenvolvidas atividades, por exemplo, de ourives, prateiros, tecelagem, olaria, engenho, curtume, carvoaria, entre outras.

Em 1759, com a expulsão dos padres jesuítas pelo marquês de Pombal, a Fazenda de Santa Cruz tornou-se propriedade real e, em seguida, imperial. Nesse período, por distar cerca de sessenta quilômetros do centro do Rio de Janeiro, o local servia de residência de veraneio para a família imperial. Por essa razão, instalaram-se residências para os membros do governo e fornecedores de bebida, coches e animais de montaria. Dessa forma, formaram-se povoados com residências, vendas e casas de comércio, até que se alterou o estatuto de fazenda para o de povoação.

Com a abolição da escravatura, chegaram imigrantes estrangeiros para trabalhar nessa área segundo um novo modo de produção, agora plenamente capitalista, com mão de obra livre e assalariada. Em 1815, já tinham vindo os chineses, que puseram em prática a criação de bicho-da-seda e o plantio de chá. Os espanhóis também ali chegaram, formando uma aldeia de empregados nos curtumes e olarias. Muitos portugueses da região do Minho também vieram para essa área, a fim de promover a agricultura.

As modernizações também chegaram a Santa Cruz, demonstrando sua importância no modo de produção vigente. Podemos citar o fornecimento de água e a iluminação a gás e luz elétrica desde o final do século XIX. Também data dessa época a instalação de meios de transporte ferroviário, como o bonde para Sepetiba, da empresa Ferro Carril (de 1879), e o ramal de Santa Cruz da Estrada de Ferro Central do Brasil, inaugurado em 1881, a princípio com a finalidade de transportar o gado abatido no matadouro público para o centro do Rio de Janeiro.

Fridman (1999) observa que toda aquela área que compunha a Fazenda de Santa Cruz havia sido, essencialmente, propriedade pública, passando por alguns parcelamentos através de foreiros, posseiros e doaçôes. Apresentava um misto de enormes áreas com poucos retalhamentos, de modo que, no início do século XX, o que hoje é o centro de Santa Cruz pôde desenvolver-se com as atividades comerciais, ditas urbanas e de serviços. Esse centro estava envolvido por glebas de terras rurais. Ainda corroborando o que vimos em Santos (2002), sobre o espaço ser produto e condição para a reprodução da sociedade, Fridman (1999) considera que,

embora estas localidades só viessem a tomar ares verdadeiramente urbanos neste século $[\mathrm{XX}]$, todo o processo de divisão de suas terras, verificado ao longo do século XIX e mais acentuadamente nos últimos anos, foi ditado pela dominação de modo capitalista de produção, que implicou também o fim da escravatura e a proclamação da República (p. 223).

A expansão da ocupação ocorreu em momentos sucessivos, como, por exemplo, durante o governo Getulio Vargas, na década de 1930, época em que a região de Santa Cruz passou por profunda transformação, com as obras de saneamento objetivando valorizar aquelas terras. Porém, extensas terras do bairro de Santa Cruz que fizeram parte da Fazenda Nacional de Santa Cruz ainda são de propriedade pública. Desse modo, temos ali algumas instalaçôes estatais, como a Base Aérea de Santa Cruz, o antigo aeroporto Bartolomeu Gusmão, construído em 1934 para operar uma linha aérea entre Brasil e Europa, pela Luftschiffbau Zeppelin. Ainda hoje, é possível ver o marco histórico desse aeroporto, com o Hangar do Zeppelin, localizado nas dependências da base. Essa edificação foi tombada 
pelo Instituto do Patrimônio Histórico e Artístico Nacional (Iphan) em 14/03/1998 (Processo no 994-T-8). Em 1941, o aeroporto foi transformado em base aérea, que ainda está ativa nos dias atuais, abrigando as unidades do $1^{\circ}$ Grupo de Aviação de Caça (1 $\left.{ }^{\circ} \mathrm{GAvCa}\right)$ e do $1^{\circ}$ Esquadrão do $16^{\circ}$ Grupo de Aviação (1\%/16 GAv), ambos da Força Aérea Brasileira (FAB).

Com as obras de saneamento e a promoção de salubridade, foram criadas colônias agrícolas, as quais proporcionaram dinamismo econômico para os produtores. Em 1938, chegaram as primeiras famílias japonesas de Moji das Cruzes (SP) para ocupar o recém-criado Núcleo Colonial e colocar em prática novas experiências na agricultura local. Essa colônia fica entre as estradas Reta do Rio Grande e Reta de São Fernando, as quais compõem a atual zona agrícola. A produção era tão grande que abastecia toda a cidade do Rio de Janeiro, conferindo a Santa Cruz o título de celeiro do então Distrito Federal (Fridman, 1999, p. 225).

Nessa primeira metade do século XX, havia ainda produção citricultora em sítios e chácaras, ou seja, houve um fracionamento das fazendas existentes, promovendo, assim, a intensificação do uso do solo na década de 1940. Após, com a crise da citricultura, promoveu-se mudança no uso do solo, de rural para urbano, havendo um surto de urbanização. Essa crise, segundo Soares (1952), estava associada à queda da exportação de laranja para a Europa, principal comprador do produto, com a eclosão da Segunda Guerra Mundial. Além disso, não havia uma infraestrutura frigorífera no porto para conservar os produtos até o momento da exportação, o que gerava perdas e levava ao encarecimento da produção local em comparação aos outros países. Passada essa fase, nas décadas de 1950 e 1960, observa-se o parcelamento das chácaras citricultoras em lotes sem benfeitorias e, portanto, acessíveis a uma camada da população com condições de arcar com os custos de uma compra parcelada de terrenos no mercado informal de terras, pois eram vendidos, pelos pequenos proprietários, sem infraestrutura, registro geral de imóveis etc.

No contexto urbano, cabem algumas considerações sobre as atividades agrícolas implementadas em nossa área de estudo. Sobre a agricultura que persiste no ambiente urbano, dentro do limite da cidade, e "resiste ao avanço da cidade", Bicalho (1992) afirma que tal fenômeno está integrado a um processo maior, o do próprio crescimento urbano. A autora ainda observa que isso deve ser entendido de forma mais abrangente, em relação à capitalização da agricultura em geral. Portanto, o comportamento do que denominou agricultura metropolitana é resulta da influência da cidade, que tanto pode ser positiva como negativa, e ainda das condiçóes da própria agricultura. Embora a autora veja no produtor rural a atuação dessas forças, através de sua tomada de decisão, devemos observar que esse não é o único determinante, nem está deslocado do contexto. Na realidade, segundo a concepção do espaço político (Léfebre, 2008), são vários os agentes que, por meio de suas decisões e interesses, determinam o espaço social e sua materialização.

$\mathrm{Na}$ cidade do Rio de Janeiro, temos visto a força do capital imobiliário e do Estado, ao promover a reestruturação da cidade, bem como da RMRJ, como salientado por Abreu (2006). Deve-se acrescentar o fato de eles também serem agentes portadores de interesses diversos, ora atuando como produtores, ora como especuladores imobiliários. Deve-se levar em conta o fato de que, antes de tudo, são proprietários de terras cujos lucros são exponenciados na conversão do solo para uso urbano. Isso é corroborado pela existência de muitas propriedades precárias com produtores absenteístas, a indicar uma espera pela especulação imobiliária, com a mudança de uso do solo, de rural para urbano. 


\section{0 bairro de Santa Cruz, RJ}

Tanto no espaço urbano como no entorno, as atividades agrícolas frequentemente simbolizam o interesse em manter a propriedade da terra, à espera de uma eventual valorização, a fim de auferir lucros elevados, com a transformação do solo, de rural para urbano. $\mathrm{Na}$ área oeste da cidade do Rio de Janeiro, incluindo o bairro de Santa Cruz, no período de 1930 a 1960, observaram-se políticas de assentamento agrícola de pequenos produtores rurais e políticas de intervenção associadas à instalação das colônias agrícolas. A partir de então, Santa Cruz e adjacências vêm passando por várias fases de urbanização.

$\mathrm{Na}$ década de 1930, com o aumento das moradias para pessoas de baixa renda, associado à eletrificação da linha férrea, a urbanização já estava em curso, pois esses fatores possibilitavam aos trabalhadores morarem em áreas mais distantes do Centro do Rio de Janeiro. Além disso, é importante lembrar que tudo isso estava associado aos problemas com a citricultura. Já na década de 1960, o processo pode ser associado à remoção de favelas das áreas nobres da cidade, o que acabou por confirmar esse processo de transformação. Na década de 1970, com as obras de extensão da av. Brasil até a Zona Oeste, no empreendimento de formação da BR-101, foi possível incrementar o parcelamento do solo, promovendo, mais uma vez, uma fase de urbanização. Para a década de 1970, Carvalho (1999, p. 36) descreve a Zona Oeste da seguinte maneira:

A Zona Oeste permanece como espaço de transição, onde convivem processos modernos e arcaicos de ocupação [...] e onde a produção imobiliária se caracteriza pela convivência de diferentes formas de produção, tais como: autoconstrução, conjuntos habitacionais e comerciais, loteamentos com casas [...].

Os conjuntos habitacionais, assim como a construção do distrito industrial, correspondem à política estatal das décadas de 1960 e 1970 no contexto de industrialização do país. Entre esses conjuntos, citamos três: o de Antares, que apresenta uma grande favelização à sua volta; o conjunto residencial Doutor Otacílio de Carvalho Camará, mais conhecido como "Cesarão", em virtude de sua localização, ao longo da av. Cesário de Melo; e o conjunto habitacional João XXIII. Temos, então, como resultado dos processos históricos de ocupação, uma área com diversas formas de produção imobiliária justapostas, ladeadas por propriedades de cultivo e pecuária na zona agrícola, e o distrito industrial pouco ocupado. Ao todo, são 62 loteamentos irregulares e 17 favelas; dessas favelas, quatro formam complexos de favelas (Sabren - Armazém de Dados da prefeitura do Rio de Janeiro, 2000).

Com isso, podemos considerar as intervençōes do Estado no que diz respeito ao ordenamento territorial para uso do solo. Segundo o Decreto Municipal no 322, de 3 de março de 1976, o bairro de Santa Cruz possui uma extensa zona industrial, conhecida como Distrito Industrial de Santa Cruz. Em seu território, também está estabelecido o Distrito Industrial de Palmares, que se estende até o bairro de Paciência. Além disso, o bairro apresenta uma Zona Especial de administração e governo (ZE 7), parte de uma Zona Especial de reserva florestal (ZE 1), que corresponde uma pequena parte da serra do Cantagalo, na divisa do bairro com Guaratiba. Possui ainda uma extensa Zona Residencial (ZR 2, ZR 4 e ZR 6).

$\mathrm{Na}$ área central do bairro, encontramos exemplo de uma das situações que interferem na possibilidade de reprodução do espaço de acordo com os interesses capitalistas: a formação de uma circunscrição denominada Apac (Área de Proteção do Ambiente Cultural), de acordo com o Decreto Municipal no 12.524 , de 9 de dezembro de 1993. Isso porque a área contém valiosos exemplares arquitetônicos como testemunho das várias fases de sua ocupação, desde a época da Fazenda Santa 
Cruz, no século XVI, passando pela instalação do centro urbano no século XIX, até a década de 1960. Assim, em virtude desse histórico, os elementos arquitetônicos não podem ser demolidos, o que gera competição acirrada com novos usos. É um bom exemplo o antigo solar da família Araújo, hoje incorporado ao shopping Santa Cruz (Foto 1). Esse quadro nos permite perceber os conflitos no espaço para a produção e a reprodução de acordo com os interesses de cada agente social.

Entre os fixos que compõem a referida Apac, destaca-se a ponte dos Jesuítas, que data de 1752 (Foto 2) e foi construída com a finalidade de regular o volume de água das enchentes, portanto, é uma ponte-represa. Com quatro arcos que serviam de comportas para o controle do regime de águas do Rio Guandu, a ponte está ornamentada com colunas de granito e capitéis em forma de pinhas portuguesas, possui na parte central belas esculturas barrocas com um brasão que exibe o símbolo da Companhia de Jesus (IHS). Outro destaque é o Palacete Princesa Isabel, construído para ser sede da Fazenda Imperial de Santa Cruz em 1881. Esses abrigou a Escola Santa Isabel e hoje funciona como Centro Cultural Municipal de Santa Cruz no qual se localiza o NOPH (Núcleo de Orientação e Pesquisa Histórica) com a finalidade de manter a riqueza histórica e arquitetônica de Santa Cruz. Por fim, o Matadouro de Santa Cruz que jaz em ruínas, sendo uma parte de sua área aproveitada para abrigar as diversas instituições públicas de ensino mencionadas na página anterior.

Foto 1. Shopping Santa Cruz, solar dos Araújos

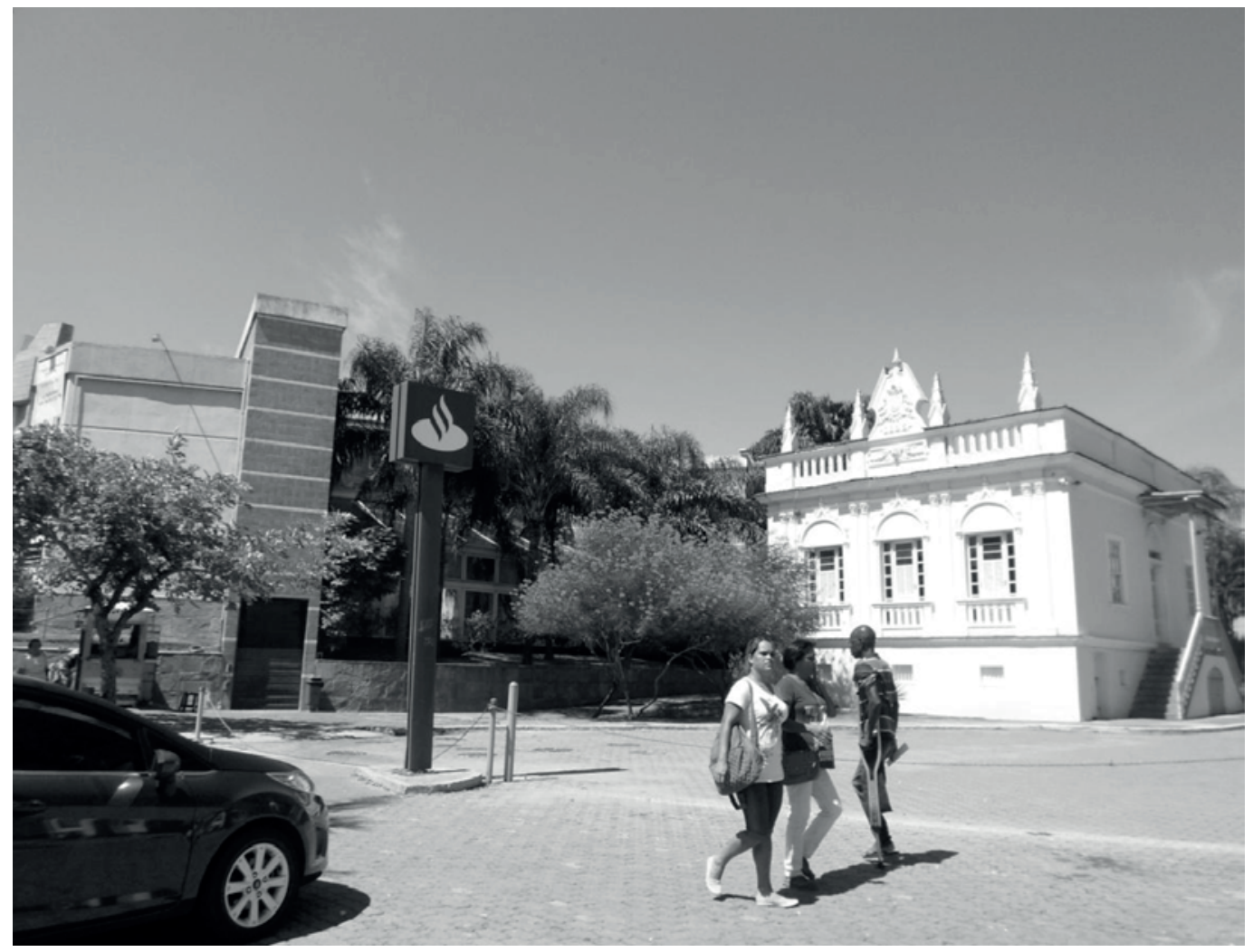

Fonte: Silva, 2016. 


\section{0 bairro de Santa Cruz, RJ}

Foto 2. Ponte dos Jesuítas, Santa Cruz (RJ)

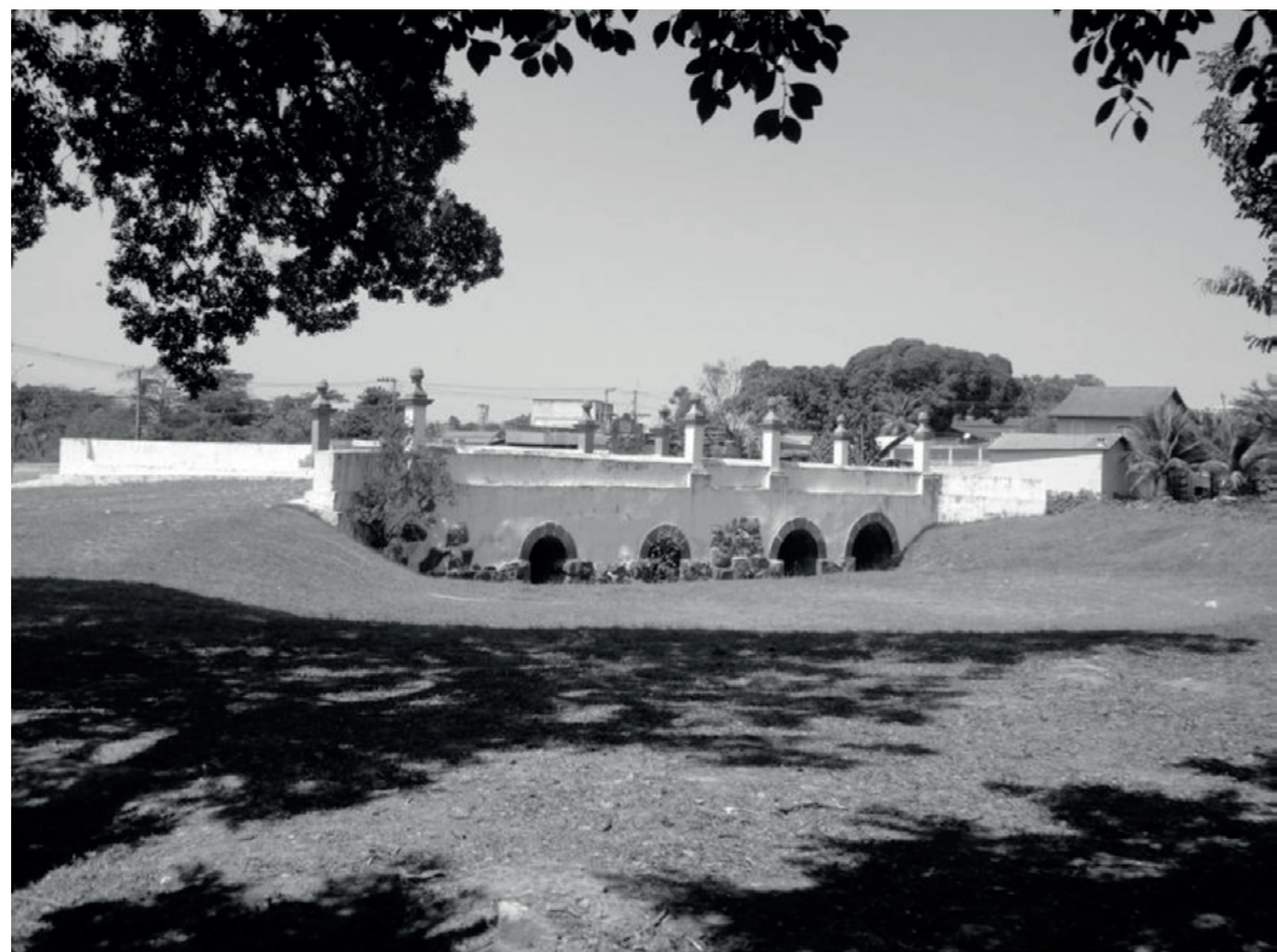

Autor: Ivo Korytowski, jun. 2006.

Essas considerações quanto ao controle de uso do solo são importantes porque configuram ações do Estado que impõem circunstâncias muitas vezes questionadas por outros agentes sociais do espaço. Por exemplo, em entrevista com o gerente Alexandre Vilela, da $8^{\text {a }}$ Gerência de Licenciamento e Fiscalização (GLF), situada na rua Álvaro Alberto Luiz, 665, Santa Cruz, fomos informados de que, diferente do bairro de Campo Grande, que tem apresentado elevados índices de construção imobiliária, o bairro de Santa Cruz apresenta alguns fatores impeditivos para empreendimentos imobiliários destinados às classes sociais média e média alta. $\mathrm{O}$ primeiro deles diz respeito à zona agrícola, que, embora possua, em sua maior parte, titulação de propriedade, não autoriza uso diverso, exceto, por concessão, como empreendimentos do Programa Minha Casa Minha Vida (PMCMV) ou a construção de galpões para armazenamento.

Por uma brecha na legislação vigente, ou seja, por não haver especificação do tipo de galpão que pode ser construído, têm-se edificado galpões para a logística de grandes lojas, que conseguem terrenos amplos a baixo custo e se comprometem a instalar infraestrutura na localidade, como, por exemplo, abertura, drenagem e pavimentação de estradas. Quanto ao problema de titulação das pro- 
priedades, observa-se que remonta às primeiras ocupações da área, que, por ter sido, após a proclamação da República, Fazenda Nacional, ${ }^{4}$ de propriedade do governo federal, era administrada pelo Incra (Instituto Nacional de Colonização e Reforma Agrária).

Um edital publicado em 18/11/2013, envolvendo a Superintendência Regional do Incra no Rio de Janeiro, lançou uma chamada pública para a restauração do acervo fundiário FNSC, situado na Zona Oeste do município do Rio de Janeiro. Conforme relatos, há mais de três mil processos de regularização da Fazenda, além de livros fundiários, livros com os nomes dos foreiros, mapas e documentos que remontam ao período imperial. Além disso, a dificuldade para a regularização decorre das diversas situações jurídicas no local. Desse modo, as áreas destinadas à atividade agrícola, como já mencionado, encontram-se, em sua maior parte, regularizadas. As áreas destinadas a uso residencial, que, por sinal, ultrapassam $50 \%$ de todo o bairro, em sua maioria não possuem títulos de propriedade. Dessa forma, tanto a falta de titulação como o zoneamento formam um elemento socioespacial que condiciona a reprodução do espaço, no que diz respeito ao setor imobiliário, nos moldes capitalistas atuais. Além disso, observa-se a prática de loteamentos irregulares e ilegais, principalmente ao longo das principais vias.

Com as recentes obras de infraestrutura, há um prognóstico de transformação local no que diz respeito à construção de novas moradias e a instalação de novos equipamentos de comércio e serviços que precisam ser analisados.

Após observarmos os aspectos da ocupação histórica do bairro de Santa Cruz, que se transfiguram em condicionantes espaciais para as dinâmicas que se vislumbram diante dos mencionados empreendimentos de infraestrutura, destacamos os dados socioeconômicos que servirão de base à análise do bairro em questão e da área na qual se encontra inserido, em um processo atual de urbanização.

\section{A caracterização socioeconômica de Santa Cruz: população, renda e educação}

Neste tópico, trazemos alguns dados referentes ao bairro de Santa Cruz em comparação com outros da cidade do Rio de Janeiro. Por acreditarmos que as condições socioespaciais construídas em tempos pretéritos permanecem e interferem na reprodução social da atualidade, percebemos dois períodos significativos: um, entre 1970 e 1980, devido aos projetos estatais que promoveram a formação da BR-101, de acordo com o quadro político-econômico desenvolvimentista do Brasil, que impactou o processo urbano na cidade do Rio de Janeiro. O outro período, entre 1990 e 2000, que Lago (2000) e Davidovich (2010) consideram como de mudanças sociais no Brasil, com implicações espaciais.

Entre as alterações no processo político e econômico, citamos a crise fiscal e financeira do Estado Nacional; o processo de privatização, que afetou diversas empresas estatais e privadas do

\footnotetext{
${ }^{4}$ A Fazenda Nacional de Santa Cruz ocupa uma área com mais de oitenta mil hectares, em nove municípios fluminenses (Rio de Janeiro, Itaguaí, Seropédica, Paracambi, Japeri, Engenheiro Paulo de Frontim, Mendes, Piraí e Rio Claro). Aproximadamente oitocentas mil pessoas vivem nessa região.
} 


\section{0 bairro de Santa Cruz, RJ}

território fluminense; a precarização do trabalho e o crescimento da vulnerabilidade do trabalhador; o aumento da desigualdade de renda; a crise habitacional, que promoveu o aumento do número e do tamanho das favelas no Rio de Janeiro. Todavia, não foi possível reunir os dados desmembrados relativos a 1970 e 1980 quanto a renda e escolaridade por bairro no município carioca. Então, embora concordemos com Lago (2000) e Davidovich (2010), no sentido das mudanças socioespaciais ocorridas após a década de 1980, consideramos que os dados referentes a 1991 e 2000 ainda exemplificam a estrutura construída nos períodos anteriores.

Nesse contexto, ao comparar nosso recorte de estudo com os bairros representativos na cidade do Rio de Janeiro, iniciamos com os dados referentes à renda. O Quadro 1 se refere aos censos demográficos de 2000 e de 2010. Assim como destacado pelos estudos de Santos e Bronstein (1978) e de Abreu (2006), observamos uma estratificação social do espaço carioca. Assim, as áreas que concentram os maiores rendimentos estão na Zona Sul e na Barra da Tijuca.

Quadro 1. Rendimento nominal familiar per capita segundo bairros (2000)

\begin{tabular}{|l|c|c|c|}
\hline Bairros & $\mathbf{2 0 0 0}$ & $\mathbf{2 0 1 0}$ & Variação em \% \\
\hline Bangu & 305,57 & 653,26 & 53,2 \\
\hline Campo Grande & 392,49 & 878,61 & 55,3 \\
\hline Centro & 737,22 & $1.533,38$ & 51,9 \\
\hline Copacabana & $1.887,34$ & $3.768,69$ & 49,9 \\
\hline Jacarepaguá & 369,77 & $1.049,42$ & 64,8 \\
\hline Madureira & 468,53 & 980,13 & 52,2 \\
\hline Méier & $1.091,88$ & $2.236,11$ & 51,2 \\
\hline Santa Cruz & 234,36 & 509,71 & 54,0 \\
\hline Guaratiba & 260,43 & 556,62 & 53,2 \\
\hline Tijuca & $1.438,51$ & $3.023,42$ & 52,4 \\
\hline Botafogo & $1.556,12$ & $3.759,53$ & 58,6 \\
\hline Barra da Tijuca & $2.722,13$ & $5.940,31$ & 54,2 \\
\hline
\end{tabular}

Fonte: IBGE, via BME (2000). Dados da Amostra do Censo 2000. Armazém de dados do Rio de Janeiro (prefeitura do Rio de Janeiro). Em 2000, o salário mínimo era de R\$ 151,00; em 2010, passou para R\$ 510,00.

No Quadro 2, observamos que a Barra da Tijuca apresenta concentração na faixa salarial entre cinco e vinte salários mínimos. Botafogo, Copacabana, Tijuca e Méier, por sua vez, apresentam certo equilíbrio, situando-se na faixa de um a cinco salários mínimos e de cinco a vinte salários mínimos. Jacarepaguá, Madureira, Bangu e Campo Grande apresentam o maior quantitativo na faixa de um a cinco salários mínimos. Santa Cruz e Guaratiba demonstram certa equivalência entre as faixas de menor renda de até um salário mínimo e de um a cinco salários mínimos. Essa análise é corroborada pelos dados apresentados no Quadro 3, no que diz respeito à média de anos de estudo por bairro, segundo o Censo de 2000. Mais uma vez, observa-se a espacialização de forma estratificada, o que aponta para certa recorrência entre renda e escolaridade, dotando o espaço de uma estrutura que se apresenta e tende a se manter e ser reproduzida. 
Quadro 2. Classes de rendimento nominal mensal segundo bairros. Município do Rio de Janeiro (2010)

\begin{tabular}{|l|c|c|c|c|c|}
\hline Bairros & Total & até $\mathbf{1}$ & $\mathbf{+ 1} \mathbf{a} \mathbf{5}$ & $\mathbf{+} \mathbf{5}$ a 20 & $\mathbf{2 0}$ \\
\hline Centro & 38.448 & 5.403 & 19.713 & 5.336 & 236 \\
\hline Botafogo & 76.628 & 4.754 & 23.611 & 25.658 & 4.486 \\
\hline Copacabana & 137.710 & 7.822 & 45.728 & 44.846 & 7.975 \\
\hline Tijuca & 150.744 & 13.374 & 51.335 & 42.738 & 4.569 \\
\hline Méier & 46.410 & 3.689 & 18.043 & 11.217 & 664 \\
\hline Madureira & 44.534 & 7.418 & 18.677 & 3.270 & 66 \\
\hline Jacarepaguá & 133.315 & 25.640 & 54.818 & 8.196 & 731 \\
\hline Barra da Tijuca & 122.947 & 3.520 & 24.293 & 43.874 & 14.892 \\
\hline Bangu & 211.068 & 44.086 & 77.412 & 8.391 & 162 \\
\hline Campo Grande & 286.527 & 51.573 & 105.927 & 19.963 & 524 \\
\hline Santa Cruz & 182.722 & 41.760 & 57.467 & 4.171 & 122 \\
\hline Guaratiba & 92.428 & 20.497 & 30.401 & 2.024 & 58 \\
\hline Total & 5.560 .655 & 943.026 & 2.019 .784 & 611.350 & 77.929 \\
\hline
\end{tabular}

Fonte: IBGE. Censo demográfico (2010). Armazém de dados do Rio de Janeiro. Prefeitura do Rio de Janeiro.

Quadro 3. Média de anos de estudo das pessoas responsáveis pelos domicílios particulares permanentes

\begin{tabular}{|l|c|}
\hline Bairros & $\begin{array}{c}\text { Média de anos de } \\
\text { estudo }\end{array}$ \\
\hline Centro & 8,96 \\
\hline Botafogo & 11,77 \\
\hline Copacabana & 11,76 \\
\hline Tijuca & 11,28 \\
\hline Méier & 11,07 \\
\hline Madureira & 7,92 \\
\hline Jacarepaguá & 6,08 \\
\hline Barra da Tijuca & 13,25 \\
\hline Bangu & 6,95 \\
\hline Campo Grande & 7,63 \\
\hline Guaratiba & 5,63 \\
\hline Santa Cruz & 6,15 \\
\hline Total & 8,29 \\
\hline
\end{tabular}

Fonte: Instituto Brasileiro de Geografia e Estatística (IBGE),

Censo 2000. Armazém de dados do Rio de Janeiro (prefeitura do Rio de Janeiro). 
O Quadro 4 aborda o Índice de Desenvolvimento Humano, que é obtido pela média aritmética simples de três índices referentes às dimensões longevidade (IDHM-longevidade), educação (IDHM-educação) e renda (IDHM-renda). Observamos que, entre os bairros com o IDH mais elevado (acima de 0,9), encontram-se Barra da Tijuca, Copacabana, Botafogo, Méier e Tijuca. Em uma condição elevada (de 0,8 a 0,89), temos os bairros do Centro, Madureira e Campo Grande. Por fim, em uma classificação média, encontram-se os bairros de Jacarepaguá, Guaratiba e Santa Cruz. Através dos dados apresentados, concluímos que o padrão socioeconômico do bairro de Santa Cruz, assim como dos demais bairros dessa parte da Zona Oeste carioca, em relação ao núcleo central da cidade e à metrópole do Rio de Janeiro, constituído no contexto desenvolvimentista, passou por algumas mudanças pontuais até a década de 2010, como é o caso de Campo Grande no que diz respeito ao aumento do número de estudantes com ensino superior e ao seu IDH, em uma classificação elevada, superando até mesmo o bairro de Jacarepaguá.

Quadro 4. Índice de Desenvolvimento Humano (IDH) por bairros

\begin{tabular}{|c|c|c|c|c|c|c|c|c|c|}
\hline 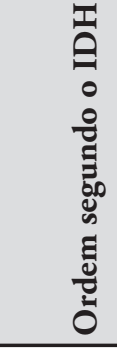 & 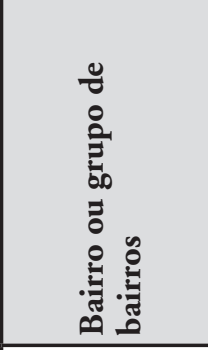 & 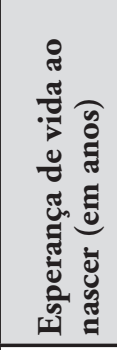 & 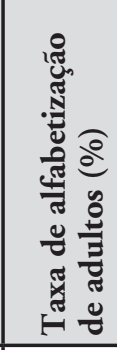 & 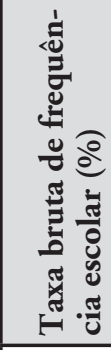 & 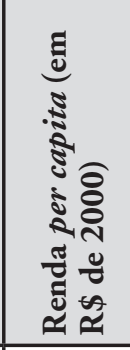 & 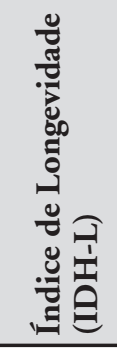 & 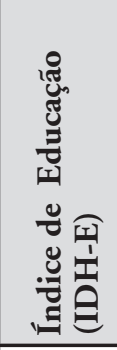 & 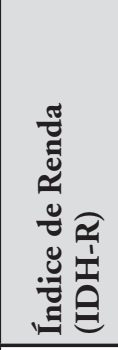 & 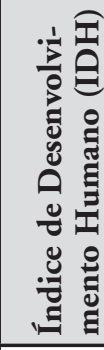 \\
\hline 8 & Barra da Tijuca & 77,84 & 99,38 & 110,09 & $2.488,47$ & 0,881 & 0,996 & 1,000 & 0,959 \\
\hline 11 & Copacabana & 77,78 & 98,48 & 107,54 & $1.623,42$ & 0,880 & 0,990 & 1,000 & 0,956 \\
\hline 13 & Botafogo & 78,25 & 98,46 & 113,01 & $1.376,47$ & 0,888 & 0,990 & 0,979 & 0,952 \\
\hline 17 & Méier & 77,37 & 99,01 & 108,63 & $1.000,16$ & 0,873 & 0,993 & 0,926 & 0,931 \\
\hline 18 & Tijuca & 75,04 & 98,02 & 107,38 & $1.204,61$ & 0,834 & 0,987 & 0,957 & 0,926 \\
\hline 32 & Centro & 76,12 & 97,58 & 99,24 & 633,36 & 0,852 & 0,981 & 0,850 & 0,894 \\
\hline 67 & Madureira & 70,97 & 96,81 & 90,42 & 419,81 & 0,766 & 0,947 & 0,781 & 0,831 \\
\hline 82 & Campo Grande & 69,80 & 95,98 & 87,42 & 351,11 & 0,747 & 0,931 & 0,751 & 0,810 \\
\hline 96 & Bangu & 69,78 & 95,45 & 82,95 & 296,55 & 0,746 & 0,913 & 0,723 & 0,794 \\
\hline 104 & Jacarepaguá & 67,51 & 90,18 & 77,14 & 331,44 & 0,709 & 0,858 & 0,742 & 0,769 \\
\hline 118 & Guaratiba & 66,66 & 90,74 & 74,37 & 234,37 & 0,694 & 0,853 & 0,684 & 0,744 \\
\hline 119 & Santa Cruz & 65,52 & 93,19 & 79,82 & 206,23 & 0,675 & 0,887 & 0,662 & 0,742 \\
\hline
\end{tabular}

Fonte: Dados básicos: IBGE, microdados dos Censos Demográficos 1991 e 2000.

Cálculos: Convênio IPP/IUPERJ/IPEA e FJP-MG.

Armazém de dados do Rio de Janeiro (prefeitura do Rio de Janeiro). 

de estudo.

Observamos alguns contextos históricos político-econômicos que exercem influência na área

Até a década de 1960, verificamos que nosso objeto de estudo sempre esteve funcionalmente integrado como produtor de alimentos na cidade do Rio de Janeiro.

No período de 1970-1980, constatamos o final do modelo econômico nacional, caracterizado pela atuação e o financiamento estatal do desenvolvimento econômico, pautado na industrialização tanto de base como de bens de consumo. Para tanto, verificamos que houve investimento na construção e ampliação de importantes rodovias, como, por exemplo, a BR-101. Esse contexto influenciou a formação de um espaço metropolitano de modelo dual: o núcleo e suas sucessivas periferias, ou centro-periferia. Temos, então, o bairro de Santa Cruz com uma composição populacional de baixa renda e um grau de instrução que reafirma a descrição de Santos e Bronstein (1978) e de Abreu (2006).

O período que vai de 1990 a 2000, segundo Lago (2000), resulta: da reestruturação social e econômica vivenciada no Brasil a partir da década de 1980, percebida como uma crise fiscal e financeira; da privatização das empresas estatais; da precarização do trabalho; do empobrecimento da população e do aumento da desigualdade de renda, entre outros fatores, com as implicações espaciais na estrutura metropolitana anterior. Além disso, o momento atual é identificado por Davidovich (2010) como aquele em que os investimentos em infraestrutura de rodovias e portos alçam o Rio de Janeiro à condição de local estratégico para a economia globalizada.

Assim, podemos afirmar, de acordo com nossas observações, que a cidade do Rio de Janeiro apresenta um quadro de desigualdade espacial em diferentes escalas no tocante aos bairros e às regiōes administrativas, com diferentes variáveis apontando para um modelo extremamente centralizador. No contexto socioeconômico e em relação ao centro, a área em que se insere o bairro de Santa Cruz é classificada como periferia, apresentando grande discrepância em relação às áreas centrais no que diz respeito a renda e educação.

O investimento em infraestrutura de transporte aponta para uma transformação no bairro que se denomina expansão urbana. Podemos traçar um paralelo entre essa discussão e o que Silva (1996) afirma quando da análise da expansão urbana na cidade do Rio de Janeiro entre as décadas de 1970 e 1980. Silva assinala que a ação do capital imobiliário redistribuiu as camadas da população de acordo com determinadas estratégias, com vistas à incorporação de novas áreas. Desse modo, observou o deslocamento da atuação do capital incorporador da Zona Sul para a Zona Norte carioca em dois setores: região da Tijuca e subúrbios da Central; e para a parte sul da Zona Oeste carioca, compreendida por Barra da Tijuca, Jacarepaguá e Recreio.

Tal movimento consistiu na redução de investimentos nas áreas mais tradicionais, com vistas à intensificação nos bairros considerados indesejáveis, distantes do Centro ou de difícil acesso. Nesse sentido, houve uma ação do Estado, no sentido de promover a construção e a reforma de algumas vias, como, por exemplo, a estrada Lagoa-Barra na década de 1960; a duplicação da estrada Grajaú-Jacarepaguá; a pavimentação da av. Alvorada; melhorias na estrada da Grota Funda, ligando essa área a Guaratiba, Campo Grande e Santa Cruz, propiciando, assim, a valorização de terras anteriormente apropriadas por empresas privadas. Quando falamos da Grota Funda, imaginamos que essa é uma antevisão do que ocorre na atualidade. As novas bases materiais de infraestrutura relacionadas ao túnel da Grota Funda e à TransCarioca abre áreas ao norte do maciço da Pedra Branca para 


\section{0 bairro de Santa Cruz, RJ}

o mercado imobiliário, o que demanda pesquisas que investiguem as especificidades de cada recorte constituinte.

Assim, percebemos que existem novos conteúdos a indicar que o processo envolve mais do que expansão urbana. Considerando que existem outros processos que extravasam a cidade e a Região Metropolitana, Pereira (2015) registra que os novos artefatos nos apontam a emergência do metropolitano como condição para a reprodução do capital. Exemplifica com os grandes empreendimentos imobiliários, como centros empresariais, escritórios, flats, shopping centers, hotéis etc. Em conformidade com essa teoria, em Santa Cruz temos a proposta de construção de um complexo com usos múltiplos na av. Brasil, o que sugere o potencial dessa localidade, em virtude do acesso direto à rodovia e ao ARMRJ, além de sua proximidade com a Barra da Tijuca, viabilizada pelo túnel da Grota Funda. O projeto do Complexo Nova Santa Cruz, executado pelo Grupo Creative (empresa brasileira do segmento imobiliário e da construção civil com sede em São Paulo e atuação nacional), faz referência à ação estatal para dotar a área da infraestrutura necessária de conexão, criando um novo eixo de desenvolvimento, já integrado também aos municípios vizinhos e ao novo porto de Itaguaí - leia-se um novo eixo de expansão para especulação imobiliária.

Destaca-se, ainda, que está prevista a instalação de uma universidade, visto que uma das características atuais da metropolização e do reforço da metrópole é a dotação de equipamentos para a produção de conhecimento. Nessa mesma direção, a Bio-Manguinhos está se expandindo e vai operar uma nova planta no Distrito Industrial de Santa Cruz - o Complexo Industrial de Biotecnologia em Saúde (CIBS) -, com o objetivo de ampliar a oferta de vacinas e biofármacos para os programas públicos de saúde. $\mathrm{O}$ novo campus abrigará um centro de processamento final e áreas dedicadas a garantia e controle de qualidade, visando aumentar a possibilidade de parcerias voltadas ao desenvolvimento tecnológico e à transferência de tecnologia, aumentando, assim, a competitividade do Brasil no setor de Biotecnologia.

Ademais, nos anúncios do Codin, percebemos acentuado interesse em Santa Cruz para instalar diversas indústrias, como Rolls-Royce, Champion Technologies, Jeumont, Oil States, o Grupo Lafarge e a Gypsum Drywall, pertencente ao grupo Etex. Ou seja, a partir de um espaço historicamente construído, Santa Cruz se apresenta como uma área que apresenta um contexto específico, que, em face de sua localização, torna-se atraente para investimentos com características de metropolização. Sua diferenciação em relação às demais áreas é a localização, nas proximidades do porto de Itaguaí e de importantes rodovias. Além disso, possui extensas áreas que estão se voltando aos mais diversos usos, de modo que observamos certa concentração dos investimentos relacionados a equipamentos industriais nesse bairro mais do que nas demais áreas da bacia de Sepetiba. Essa dinâmica reforça a concentração no núcleo metropolitano, ainda que seja na periferia interna.

Segundo a SMU do Rio de Janeiro, de 2009 até julho de 2015, tivemos no bairro de Santa Cruz 16.064 novas unidades construídas, sendo que 1.804 são destinadas à faixa de renda entre três e seis salários mínimos; ${ }^{5}$ 1.563, para os que ganham entre seis e dez salários mínimos; e a maioria,

\footnotetext{
5 Tomamos como referência o salário mínimo nacional de 2011 (quando a segunda fase do PMCMV foi implementada), de acordo com a MP no 516/10 e o DOU de 31/12/2010. A partir de 1/1/2011, o valor passou para $\mathrm{R} \$ 540,00$. Após, tivemos mais quatro reajustes do salário mínimo nacional (SM), sendo que o
} 
12.697, voltada à renda entre zero e três salários mínimos. Se compararmos esse quantitativo com o total de empreendimentos MCMV no mesmo período para a cidade do Rio de Janeiro - 35.121 unidades -, concluímos que, em média, 50\% estão em Santa Cruz, com ênfase na produção voltada à faixa de renda mais baixa. Podemos pensar que essa é uma estratégia para levar os mais pobres para bem longe das áreas mais proeminentes da cidade carioca, porém afirmamos que esse é um modo de pensar reducionista, que não leva em conta os diversos elementos aí envolvidos.

Neste ponto, indagamos quanto à sobreposição de espacialidades que demandam investigação e nos suscitam as seguintes questões: em quais aspectos esse momento se diferencia dos anteriores? Quais são seus contextos políticos e econômicos, nacionais e estrangeiros? De acordo com a estrutura espacial de ocupação urbana resultante de momentos pretéritos, quais mudanças observamos atualmente no bairro em estudo ou na periferia intermediária, como na Região Metropolitana do Rio de Janeiro? Essas questões tornam-se a base para pesquisas futuras, com vistas a investigar o bairro de Santa Cruz no contexto dos processos de urbanização/metropolização no Rio de Janeiro.

\section{Considerações finais}

Ao analisarmos o espaço do bairro de Santa Cruz na cidade do Rio de Janeiro, deparamos com alguns elementos que nos instigaram. Entre eles, aqueles que nos remetem a momentos anteriores, como, por exemplo, alguns dos conjuntos habitacionais que datam do período industrial da década de 1970, época em que os investimentos urbanos industriais se caracterizavam por melhoria nos acessos e nas vias, bem como na promoção de habitação formal e informal para a força de trabalho.

Concomitantemente, observou-se a formação de loteamentos irregulares e clandestinos no entorno desses conjuntos habitacionais e em outras extensões do bairro. Com a precarização das condições de trabalho a partir da década de 1980, houve adensamento desses últimos, de modo que, no bairro de Santa Cruz, existem muitas favelas e complexos de favelas que se estendem horizontalmente, acompanhando o relevo da região, com predomínio das planícies flúvio-marinhas e poucas elevações residuais no alinhamento dos maciços costeiros. Essa conformação é permeada por áreas vazias ou com algumas atividades agrícolas, demandando análise tanto da configuração espacial atual como das mudanças em curso. Isso porque também notamos alguns elementos atuais, como, por exemplo, a construção do túnel da Grota Funda, a implantação da linha de BRT TransOeste e a implantação da CSA, ao mesmo tempo que, no município limítrofe de Itaguaí, temos a remodelação do porto de Itaguaí e a construção do Arco Rodoviário Metropolitano, o qual liga o referido bairro e adjacências à refinaria de Duque de Caxias e ao Comperj.

último passou a vigorar em 1/1/2015, no valor de R $\$ 788,00$. No site http://www.brasil.gov.br/economia-e-emprego/2015/07/ há uma divulgação da fase três do programa, na qual haverá reajuste. Porém, a fase dois, que ainda está em vigor, estabelece as faixas de renda tomando por base o salário mínimo de 2011, portanto a faixa 1, de zero a três salários, engloba as famílias que ganham até $\mathrm{R} \$ 1.600,00$; a faixa 2, de três a seis salários mínimos, para os que ganham entre $\mathrm{R} \$ 1.600,00$ e $\mathrm{R} \$ 3.725,00$; e a faixa 3 abrange aqueles que têm renda familiar entre $\mathrm{R} \$ 3.725,00$ e $\mathrm{R} \$ 5.000,00$. 


\section{0 bairro de Santa Cruz, RJ}

Todo esse cenário nos leva a entender Santa Cruz como um espaço híbrido (Santos, 2004), em que se observa uma justaposição de temporalidades. Porém, com a pretensão de entender o processo que promove essa formação, detivemo-nos no exame da metropolização, que ocorre de acordo com várias dinâmicas e escalas, aí incluída a do bairro.

Como especificidades locais, temos o fato de o bairro apresentar extesnsas áreas destinadas a usos específicos, como o Distrito Industrial de Santa Cruz, as zonas agrícolas, que permitem a construção de galpões e de moradias para fins sociais, e ainda as zonas residenciais, que, em grande parte, não tem titularidade, atendendo a empreendimentos imobiliários. Essa última circunstância possibilitou ampla ocupação por loteamentos irregulares e clandestinos, o que complexificou o espaço, apresentando, inclusive, certo grau de dificuldade para se reconhecer a posse legal de seus ocupantes.

Em face de sua localização, no extremo oeste carioca, e das circunstâncias aqui expostas, até 2005 não havia muito interesse no bairro para expansão imobiliária. Na visita que fizemos à 8a GLF, o gerente local, sr. Alexandre Vilela, relatou-nos a dificuldade de licenciamento para esses empreendimentos, em virtude da já citada falta de titularidade de propriedade dos terrenos.

Diante de todo o exposto, no futuro será necessário pesquisar o recorte espacial de Santa Cruz, a fim de fazer um levantamento da situação fundiária dos terrenos, com o objetivo de mapear as áreas residenciais que possuem ou não titularidade. Também será preciso visitar as áreas agrícolas, buscando entender de que modo ocorre a produção agrícola urbana local, bem como os conflitos e interesses entre a manutenção do espaço rural no urbano e o espaço urbano avançando sobre o rural, como vimos em Bicalho (1992).

Analisamos, aqui, o recorte de Santa Cruz no contexto da cidade do Rio de Janeiro, inserido na conjuntura socioeconômica em relação à Área Central. O bairro é considerado periferia e apresenta inúmeras desigualdades no que diz respeito à renda e à educação. Buscando analisar em quais aspectos o atual momento se diferencia dos anteriores nos sentidos político e econômico, de acordo com os dados apurados quanto às licenças concedidas, observamos que o bairro de Santa Cruz se destaca potencialmente para novas construçôes imobiliárias em comparação a outros bairros da cidade do Rio de Janeiro.

Ressaltamos que o bairro de Santa Cruz, mesmo sendo uma área interna do núcleo metropolitano, dispõe de terrenos amplos e acessíveis que, embora apresentem alguns impeditivos, representam uma área propícia para a expansão urbana, despertando interesse para fins de capital imobiliário. Devido à sua localização estratégica em relação aos investimentos de infraestrutura, o bairro constitui área de interesse para a instalação de indústrias, galpões logísticos, equipamentos de comércio e serviços e lazer. Os empreendimentos imobiliários decorrem, inclusive, do número crescente de empresas que estão sendo implantadas na região.

Sua localização no espaço intraurbano do Núcleo Metropolitano lhe confere maior tendência a receber investimentos do que os municípios que, junto com ele, integram a bacia de Sepetiba. Esse quadro promove a ideia de que, ao longo do processo, teremos outras mudanças que irão demandar acompanhamento e verificação quanto a mobilidade, densidade, crescimento demográfico e composição socioeconômica. 
Diante do exposto, pensamos em uma agenda de futuras pesquisas, como, por exemplo, como já dito, examinar e mapear os aspectos relacionados aos problemas fundiários no bairro, contrapondo a legislação de uso do solo vigente com a titularidade de propriedade ou sua ausência nos terrenos destinados a uso residencial. Temos em mente ainda analisar as áreas de uso agrícola, a fim de entender eventuais mudanças no futuro, diante da produção imobiliária local. A esse respeito, também pretendemos mapear os conjuntos habitacionais, as zonas residenciais com e sem titularidade, as zonas agrícolas, as industriais e as zonas destinadas a fins especiais. Outra ação visada como continuidade das pesquisas em Santa Cruz consiste em levantar dados e mapear o quantitativo e os tipos de empresas que já estão instaladas, bem como aquelas que vêm consultando Codin e $8^{\circ}$ GLF para futuras instalações de seus equipamentos de produção.

Ao realizarmos pesquisas no bairro de Campo Grande e de Santa Cruz, ${ }^{6}$ reafirma-se nosso interesse pela AP5, pois reconhecemos as diferenças entre os bairros que a compõem. A AP5 é subdividida pela administração municipal da seguinte forma: na AP5.3, temos os bairros de Santa Cruz, Sepetiba, Paciência, Guaratiba, Barra de Guaratiba e Pedra de Guaratiba; na AP 5.2, Cosmos, Inhoaíba, Campo Grande, Senador Vasconcelos e Santíssimo; na AP 5.1, Bangu, Senador Camará, Padre Miguel, Realengo, Magalhães Bastos, Vila Militar, Deodoro, Campo dos Afonsos, Gericinó e Jardim Sulacap. Buscamos identificar o que diferencia os bairros da AP 5.3 daqueles que integram a AP 5.2 em relação ao setor imobiliário. Essa indagação decorre da intensa expansão imobiliária em Campo Grande para habitantes de classe média, fato destacado por Macedo (2002), Lago e Mammarella (2009), Miranda e Miller (2010), Cardoso e Lago (2015) e Ribeiro e Ribeiro (2015). Tomando-se a ideia de que a construção do túnel da Grota Funda e do BRT TransOeste abriu uma fronteira para a expansão imobiliária, como entender a produção ainda tímida nos bairros de Guaratiba, Pedra de Guaratiba, Barra de Guaratiba e Sepetiba?

\footnotetext{
${ }^{6}$ A autora vem desenvolvendo pesquisas na Zona Oeste carioca que integra a AP5. No curso de pós-graduação lato sensu em Políticas Territoriais no Estado do Rio de Janeiro, oferecido pelo Instituo de Geografia da Universidade do Estado do Rio de Janeiro, foi examinado o transporte público na urbe carioca, especificamente no bairro de Campo Grande, relacionando-o com o processo de segregação socioespacial. Em 2009, novamente a respeito do bairro de Campo Grande, no curso de Pós-Graduação stricto sensu em Geografia na Pontifícia Universidade Católica do Rio de Janeiro, foi feita uma pesquisa relacionando os processos de segregação e de centralização, com a finalidade de perceber a produção do espaço urbano carioca de acordo com o desenvolvimento geográfico desigual, ressaltando a forma paradoxal em que o recorte analisado se constitui.
} 


\section{Referências}

ABREU, Maurício de Almeida. A evolução urbana do Rio de Janeiro. Rio de Janeiro: IPP, 2006. $156 \mathrm{p}$.

BICALHO, Ana Maria de Souza Mello. "Agricultura e ambiente no município do Rio de Janeiro". In ABREU, Mauricio de Almeida (org.). Natureza e sociedade no Rio de Janeiro. Rio de Janeiro: Secretaria Municipal de Cultura, Turismo e Esportes, Departamento Geral de Documentação, Divisão de Editoração, 1992, pp. 285-316.

CARDOSO, Adalto Lúcio e LAGO, Luciana Correa do. "Dinâmica Imobiliária: Estado e capital imobiliário". In RIBEIRO, Luiz Cesar de Queiroz (org.). Rio de Janeiro: transformaçôes na ordem urbana. 1 ed. Rio de Janeiro: Letra Capital/Observatório das Metrópoles, 2015, pp. 320-53.

CARVALHO, Elsa Esteves. Análise espaço-temporal das RAs de Santa Cruz, Campo Grande e Guaratiba (tese). UFRJ, 1999.

DAVIDOVICH, Fany. "Estado do Rio de Janeiro: o urbano metropolitano. Hipóteses e questões", Geo UERJ, ano 12, n. 21, v. 2, 2. sem. 2010. Disponível em: http://www.e-publicacoes.uerj.br/ index.php/geouerj/article/view/1474.

FREIRE, Quintino Gomes. "Mapa do Rio de Janeiro com a legislação por bairro”. Diário do Rio. Disponível em: http://diariodorio.com/mapa-do-rio-de-janeiro-com-a-legislao-por-bairro/. Acesso em: 7 mar. 2016.

FRIDMAN, Fania. Donos do Rio em nome do rei: uma história fundiária da cidade do Rio de Janeiro. Rio de Janeiro: Jorge Zahar/Garamond, 1999. 304p.

GAMA, Sonia Vidal Gomes da. Mapeamento digital da incompatibilidade de usos do solo na XIX RA de Santa Cruz: municipio do Rio de Janeiro (tese). UFRJ, 1998.

IBGE. Censo demográfico 2000.

- Censo demográfico 2010.

INCRA. "Incra/RJ publica edital para recuperação de acervo histórico da Fazenda Nacional de Santa Cruz. 2013”. Disponível em: http://www.incra.gov.br/. Acesso em: 11 mar. 2015.

KORYTOWSKI, Ivo. "Monumentos de Santa Cruz". 1 jun. 2006. Disponível em: http://literaturaeriodejaneiro.blogspot.com.br/2013/06/santa-cruz-uma-paixao.html. Acesso em: 17 mar. 2015.

LAGO, Luciana Corrêa do. Desigualdades e segregação na metrópole: o Rio de Janeiro em tempo de crise. Rio de Janeiro: Revan/Fase, 2000. 240p.

LÉFÈBVRE, Henri. The production of space. Oxford, UK: Blackwell, 1994, pp. 1-67.

- Espaço e politica. Belo Horizonte: UFMG, 2008. 192p.

MACEDO, Andréia Pereira de. Produção Imobiliária e segregação na periferia do Rio de Janeiro: o bairro de Campo Grande (dissertação). UFRJ, 2002

MACHADO, Lia Osório e CASTRO, Murilo C. de. "Diagnóstico socioeconômico da bacia de hidrográfica de Sepetiba - RJ. 1996”. Disponível em: http://igeo-server.igeo.ufrj.br/retis/in- 
dex.php/autor/lia-osorio-machado/diagnosticosocioecoomico-da-bacia-hidrografica-de-sepetiba/. Acesso em: 18 jul. 2011.

MIRANDA, Gisele dos Santos de e MÜLLER, Clarisse da Cunha. "As transformações locais no 'bairro' Rio da Prata, em Campo Grande, a partir da expansão de condomínios fechados: uma perspectiva multiescalar da dinâmica espacial da cidade do Rio de Janeiro - RJ”. Encontro Nacional de geógrafos, 16, 2010, Rio Grande do Sul. Anais... Rio Grande do Sul: [S.n.], 2010. Disponível em: www.agb.org.br/evento/download.php?idTrabalho=2763. Acesso em: 7 fev. 2015.

PEREIRA, Paulo Cesar Xavier. "Reestruturação imobiliária e produção do espaço metropolitano". Simpósio Internacional de Metropolização do espaço, gestão territorial e relações urbano-rurais, 2, 2014, Rio de Janeiro. Metropolização do espaço: processos e dinâmicas. Rio de Janeiro: Simerger, 2014. Disponível em: http://simegerpucrio.wix.com/simeger. Acesso em: 12 mar. 2015.

RIBEIRO, Luiz Cesar Queiroz e RIBEIRO, Marcelo Gomes. "Segregação residencial: padrões e evolução". In - (org.). Rio de Janeiro: transformaçôes na ordem urbana. 1 ed. Rio de Janeiro: Letra Capital/Observatório das Metrópoles, 2015, pp. 163-92.

RIO DE JANEIRO. Secretaria de Obras do Estado do Rio de Janeiro. Arco Metropolitano do Rio de Janeiro. Disponível em: http://www.mma.gov.br/port /conama/reuniao/dir867/ApresentARCORodv_GovRJ.pdf. Acesso em: 22 abr. 2014.

- Sabren. Portal Geo/Sabren. Disponível em: http://www.armazemdedados.rio.rj.gov.br. Acesso em: 20 jul. 2014.

—. Armazém de Dados da Prefeitura do Rio de Janeiro. Disponível em: http://www.armazemdedados. rio.rj.gov.br. Acesso em: 20 jul. 2014.

—. Câmara Municipal. Decreto Lei n.o 12524 de 09 de dezembro de 1993. "Cria a Área de Proteção do Ambiente Cultural do Bairro de Santa Cruz, XIX Região Administrativa, e dá outras providências". Disponível em: http://mail.camara.rj.gov.br/APL/Legislativos/scpro0711.nsf/449a94f8ca1f12 5a832566ec00172e93/a429f6ca78b4afcb832578b6005c928b?OpenDocument. Acesso em: 21 set. 2015.

SANTOS, Carlos Nelson Fernandes dos e BRONSTEIN, Olga. "Metaurbanização: o caso do Rio de Janeiro". Revista de Administração Municipal, Rio de Janeiro, v. 25, n. 149, pp. 6-34, out.-dez. 1978. SANTOS, Milton. Por uma geografia nova. São Paulo: Hucitec, 2002. 285p.

- A natureza do espaço: técnica e tempo, razão e emoção. 4 ed. 1. reimpr. São Paulo: USP, 2004. 367p.

- Espaço e método. 5 ed. São Paulo: USP, 2008. 120p.

SILVA, Carlos Alberto F. da. "A promoção imobiliária recente no município do Rio de Janeiro", Revista Território, v. 1, n. 1, 1996 , pp. 43-57.

SILVA, Vânia Regina Jorge da. A segregação espacial pela ótica do transporte urbano: o exemplo do bairro de Campo Grande - RJ (monografia). UERJ, 2006.

- Examinando os processos de segregação e descentralização através do transporte público na cidade do Rio de Janeiro: o exemplo de Campo Grande - RJ, 1990-2009 (dissertação). PUC-Rio, 2009.

SOARES, Maria Therezinha Segadas. "Nova Iguaçu: absorção de uma célula urbana pelo Grande Rio de Janeiro". Revista Brasileira de Geografia, ano 24, n. 2, abr.-jun. 1952, pp. 157-241. 